\title{
Glucose metabolism regulates T cell activation, differentiation, and functions
}

\author{
Clovis S. Palmer ${ }^{1 *}{ }^{\dagger}$, Matias Ostrowski ${ }^{2 \dagger}$, Brad Balderson $^{1}$, Nicole Christian ${ }^{3}$ and Suzanne M. Crowe ${ }^{1,4,5}$ \\ ${ }^{1}$ Centre for Biomedical Research, Burnet Institute, Melbourne, VIC, Australia \\ ${ }^{2}$ Instituto de Investigaciones Biomédicas en Retrovirus y SIDA, Facultad de Medicina, Universidad de Buenos Aires, Buenos Aires, Argentina \\ ${ }^{3}$ Department of Microbiology, The University of the West Indies, Kingston, Jamaica \\ ${ }^{4}$ Department of Infectious Diseases, Monash University, Melbourne, VIC, Australia \\ ${ }^{5}$ Infectious Diseases Department, The Alfred Hospital, Melbourne, VIC, Australia
}

Edited by:

Anne L. Astier, University of

Edinburgh, UK

Reviewed by:

Kenneth Frauwirth, University of

Maryland, USA

Jeff Rathmell, Duke University, USA

*Correspondence:

Clovis S. Palmer, Centre for

Biomedical Research, Burnet

Institute, 85 Commercial Road,

Melbourne, VIC 3004, Australia

e-mail:cpalmer@burnet.edu.au

${ }^{+}$Clovis S. Palmer and Matias

Ostrowski have contributed equally to this work.
The adaptive immune system is equipped to eliminate both tumors and pathogenic microorganisms. It requires a series of complex and coordinated signals to drive the activation, proliferation, and differentiation of appropriate $T$ cell subsets. It is now established that changes in cellular activation are coupled to profound changes in cellular metabolism. In addition, emerging evidence now suggest that specific metabolic alterations associated with distinct $T$ cell subsets may be ancillary to their differentiation and influential in their immune functions. The "Warburg effect" originally used to describe a phenomenon in which most cancer cells relied on aerobic glycolysis for their growth is a key process that sustain T cell activation and differentiation. Here, we review how different aspects of metabolism in T cells influence their functions, focusing on the emerging role of key regulators of glucose metabolism such as HIF-1 $\alpha$. A thorough understanding of the role of metabolism in $T$ cell function could provide insights into mechanisms involved in inflammatory-mediated conditions, with the potential for developing novel therapeutic approaches to treat these diseases.

Keywords: glucose transporter 1, PI3K, metabolism, mTOR, HIF-1 $\alpha$, immune activation, HIV, inflammation

\section{INTRODUCTION}

The immune system comprises specialized cell populations that are conditioned to respond rapidly and vigorously to antigenic and inflammatory signals. Most research has focused on these signals in guiding immune responses. Now emerging data indicate that cellular metabolism regulates immune cell functions and differentiation, and consequently influences the final outcome of the adaptive and innate immune response (1-4). The growth, function, survival, and differentiation of an activated immune cells depend on dramatic increases in glucose metabolism as fuel, a process that is directly regulated and has a profound impact on health and disease $(1,5-7)$.

Inflammatory conditions such as HIV infection results in a heightened inflammatory state that affects the availability and use of energy. This in turn influences $\mathrm{T}$ cell activation and functions $(8,9)$. Identifying the pathways that coordinate the metabolic processes during inflammatory conditions, as observed in HIV infection will potentially provide new therapeutic opportunities.

\section{METABOLIC PROFILES OF IMMUNE CELLS DURING IMMUNE ACTIVATION}

The functions of peripheral $\mathrm{T}$ cells are maintained and are intimately linked to metabolism. Specific effector functions are unable to proceed without the cell adopting the appropriate metabolic state $(10,11)$. Research into T cell metabolism has provided valuable insight into the pathways that are important for $\mathrm{T}$ cell fate, plasticity, and effector functions. T cells rapidly transition between resting catabolic states (naïve and memory $\mathrm{T}$ cells) to one of growth and proliferation (effector T cells) during normal immune responses $(10,11)$.

The commitment of an immune cell to a specific metabolic pathway depends on the particular function. This is evident in the subsets of CD4+ T cells where effector T cells and Th17 cells rely on aerobic glycolysis, while memory $\mathrm{T}$ cells and $\mathrm{T}$ regulatory cells (Treg) rely on fatty acid oxidation to produce energy (12). Aerobic glycolysis is also utilized for energy by activated dendritic cells, neutrophils, and pro-inflammatory macrophages (13).

The vast majority of evidence supporting the significance of metabolism in immune cell functions is derived mainly from in vitro and animal models. The reasons why $\mathrm{T}$ cells adopt specific metabolic programs and the impact this has on their function in the context of human diseases such as HIV infection remains unclear.

\section{HOW IS GLUCOSE USED BY IMMUNE CELLS TO PRODUCE ENERGY?}

Glucose is transported into $\mathrm{T}$ cells via the high affinity Glucose transporter 1 (Glut1), which is the major glucose transporter on $\mathrm{T}$ cells $(14,15)$. Through a rate limiting step catalyzed by hexokinase, glucose is trapped inside the cells where it is metabolized via glycolysis. During this process, each glucose molecules is broken down into pyruvate with a net production of two ATP molecules. Most non-proliferating and terminally differentiated $\mathrm{T}$ cells such as naïve and memory $\mathrm{T}$ cells completely oxidize pyruvate via the 
tricarboxylic acid (TCA) cycle to generate $\mathrm{NADH}$ and $\mathrm{FADH} 2$ that fuel oxidative phosphorylation producing 36 molecules of ATP per glucose molecule. When $\mathrm{T}$ cells are activated, pyruvate is transformed into lactate regenerating NAD+ that subsequently engages glycolytic reactions.

It may seem counterintuitive that $\mathrm{T}$ cells, which have increased demand for energy would be involved in exploiting a relatively insufficient process to generate energy. Whilst glycolysis is less efficient in generating ATP than oxidative phosphorylation, it is a rapid process occurring independently of mitochondrial function. Furthermore, a widely held assumption is that the shift from oxidative phosphorylation to increased aerobic glycolysis by rapidly proliferating $\mathrm{T}$ cells diverts the use of glucose for macromolecular biosynthesis (16).

\section{GLUCOSE METABOLISM IN NAÏVE AND ACTIVATED T CELLS}

Upon maturation in the thymus, naive $\mathrm{CD} 4+\mathrm{T}$ cells recirculate between the blood and secondary lymphoid organs. The immune quiescence of naïve $\mathrm{T}$ cells is accompanied by a catabolic metabolism, characterized by the breakdown of glucose, fatty acids, and amino acids to generate intermediate metabolites, which enter the mitochondrial TCA cycle (17). The interconversion of metabolites in the TCA cycle generates energy and reducing equivalents, which subsequently enter the oxidative phosphorylation pathway effectively increasing ATP production.

The quiescence of naïve $\mathrm{T}$ cells is interrupted upon engagement of the T Cell Receptor (TCR) by a specific antigen/MHC class II complex displayed on the surface of dendritic cells, concurrently with the recognition of costimulatory molecules by the receptor $\mathrm{CD} 28$. These two signals trigger $\mathrm{T}$ cell activation, the secretion of IL-2, cellular proliferation referred to as clonal expansion, and their differentiation into an effector phenotype. These changes in the activation status of CD4+ T lymphocytes not only require energy, but also increased demand for metabolic precursors for the biosynthesis of proteins, nucleic acids, and lipids to fuel clonal expansion and subsequent differentiation into effector cells. Therefore, efficient $\mathrm{T}$ cell activation requires profound changes in cellular metabolism $(18,19)$. In effect, energy generation through the TCA cycle and oxidative phosphorylation is interrupted and have been thought to be replaced by glycolysis, in which glucose is converted to lactate in the cytosol, even when sufficient oxygen is available to perform oxidative phosphorylation $(5,20)$.

The peculiar promotion of glycolysis in the presence of normal oxygen levels is referred to as aerobic glycolysis and it is also a hallmark of cancer metabolism $(21,22)$. Although less efficient in terms of energy production, aerobic glycolysis generates metabolic intermediates that are used in anabolic pathways required to sustain cell growth and to produce daughter cells. However, more recently the dogma that $\mathrm{CD} 4+\mathrm{T}$ cells simply switch from an oxidative to glycolytic metabolism has been challenged. Cao and colleagues demonstrated that oxidative phosphorylation is strongly induced during CD4+ T cells activation (23). By comparing CD4+ and CD8+ T cells, the researchers showed that these cells utilize distinct metabolic strategies to meet their functional demands. Following activation, CD8 $+\mathrm{T}$ cells had a higher glycolytic flux than CD4+ T cells. On the other hand, CD4+ $\mathrm{T}$ cells also induced glycolysis upon activation, but had greater mitochondrial content and oxidative metabolism than CD8+ T cells. Nevertheless their observation that glycolytic inhibition by 2 deoxy-glucose (2-DG) suppressed CD4+ T cell growth, and that rotenone inhibited both $\mathrm{CD} 4+$ and $\mathrm{CD} 8+\mathrm{T}$ cell proliferation underscores the significance of glycolysis and oxidative metabolism in $\mathrm{T}$ cell activation (23). It is therefore apparent that $\mathrm{T}$ cell activation is not accompanied merely by a switch from oxidative metabolism to glycolysis, but that both pathways are upregulated to support bioenergetic demands. This intimate interrelationship between $\mathrm{T}$ cell activation and metabolism led to the concept that changes in $\mathrm{T}$ cell metabolism are not simply a consequence of antigen-induced activation, but rather a parameter that determines $\mathrm{T}$ cell proliferation and fate decisions $(5,24)$.

\section{SIGNALING PATHWAYS REGULATING GLUCOSE METABOLISM IN T CELLS}

In activated $\mathrm{T}$ cells, the rapid induction of glycolysis is promoted by the increase in the activity of several enzymes and proteins, which are regulated at the transcriptional and posttranscriptional levels. Following T cell activation, Glut1, is translocated to the surface of CD4+ T cells (25-28). This occurs in response to the activation of the phosphoinositol-3 kinase (PI3K)-Akt pathway that triggers the recruitment of Glut1 from the cytoplasmic pool to the cell surface. Increased Glut1 expression and glucose uptake by activated $\mathrm{T}$ cells is accompanied by increased glycolysis (Figures 1A,B) (29). An abnormal transduction of Akt signaling was discovered among Fas-associated protein with death domain (FADD) knock out thymocytes, and was partly responsible for a decline in Glut1 expression, a corresponding decrease in glucose uptake, increased apoptosis, and reduced cell numbers (30). In addition, $\mathrm{T}$ cell activation accompanies induction of the mammalian target of rapamycin (mTOR) pathway. mTOR is a serine/threonine kinase that forms two multiprotein complexes, mTORC1 and mTORC2, as determined by the association with different adapter and scaffolding proteins. mTOR activation regulates a myriad of cellular functions, including growth, apoptosis, differentiation, and metabolism $(31,32)$. Recently, the mTOR pathway has generated enormous attention due to the regulation and differentiation of distinct $\mathrm{T}$ cell subsets by different mTORC complexes (7), and the considerable interest in these complexes by the pharmaceutical industry (33). Other signaling pathways that have been associated with glucose metabolism in T cells are the extracellular signal-related kinase (ERK) (34), signal transducer and activator of transcription (STAT5) (15), some MAPKinases (35), and hexokinase II (36). However, the magnitude by which these pathways regulate $\mathrm{T}$ cell metabolism may vary depending on the precise environmental conditions. Indeed, it is also likely that these pathways may also co-operate with the PI3K-Akt and mTOR pathways to regulate metabolic reprograming of $\mathrm{T}$ cells.

\section{mTOR REGULATION OF GLUCOSE METABOLISM, T CELL ACTIVATION, AND DIFFERENTIATION}

During metabolism in CD4+ T cells, activation of the mTOR by TCR/CD28 coligation interrupts catabolic metabolism by regulating fatty acid oxidation and oxidative phosphorylation (12). Concurrently, mTOR induces the transcription of many key glycolytic enzymes (37). Thus, the increase in glucose uptake due 

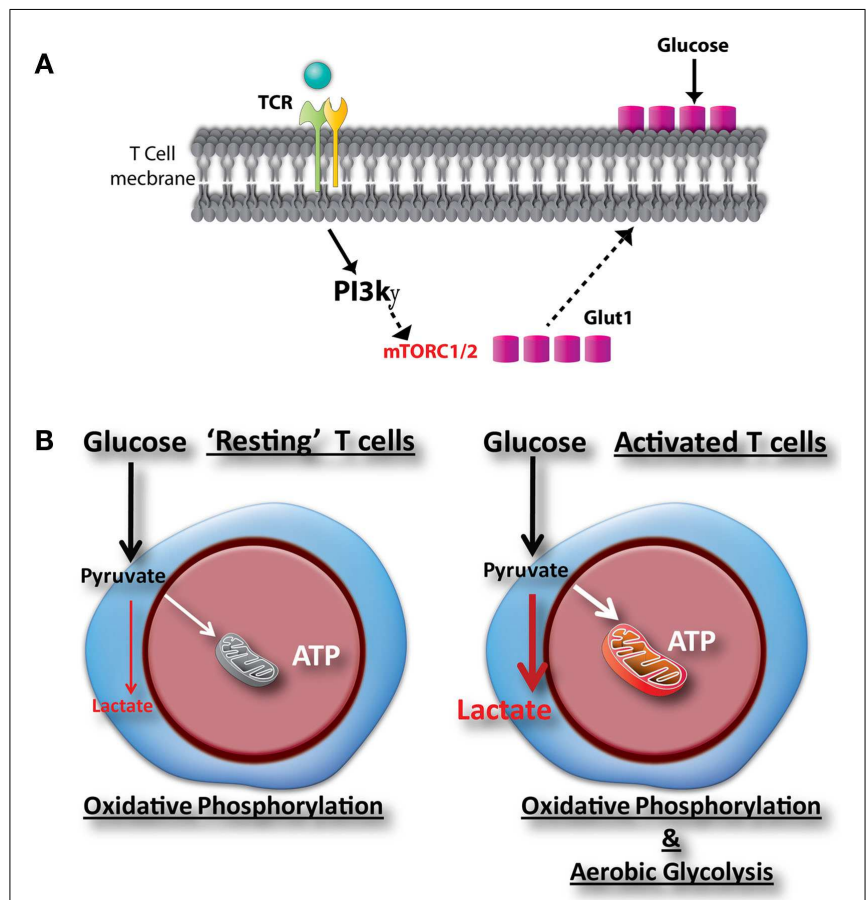

C

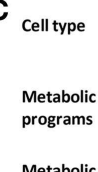

Metabolic

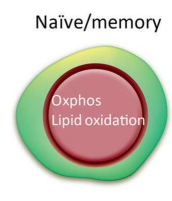

AMPK, BCl-6

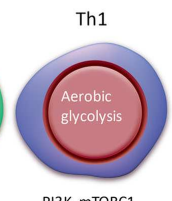

PI3K, mTORC1,
S6K, HIF-1 $\alpha$, BCl-6

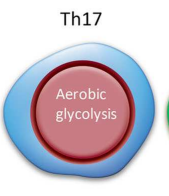

mTORC1, HIF- $1 \alpha$

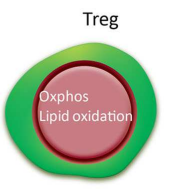

AMPK

FIGURE 1 | Glucose metabolic programs regulate glucose uptake, activation, and differentiation of CD4+T cells. (A) Mitogenic stimulation or engagement of the TCR complex activates the phosphoinositide 3-kinase (PI3K)-gamma (PI3Kg) subunit in CD4+ T cells. Activation of the PI3K $\gamma$ in $\mathrm{CD} 4+\mathrm{T}$ cells promote Glut1 trafficking from the cytoplasm to the cell membrane and increases glucose uptake to sustain activation. (B) Upon activation, T cells increase glucose uptake through Glut1, which facilitate increased oxidative phosphorylation and glycolysis to sustain cell growth and proliferation. (C) Unique metabolic changes upon differentiation of $\mathrm{T}$ cells toward different subsets, regulated by various transcription factors and signaling pathways.

to Glut1 translocation, together with enhanced transcription of glycolytic enzymes results in an important increase in the glycolytic flux. The regulation of metabolic pathways by mTOR is mainly achieved through the activation of downstream transcriptional factors, such as Bcl-6 involved in the regulation of $\mathrm{T}$ cell immune function $(38,39)$, which reinforces the current paradigm that metabolism and $\mathrm{T}$ cell function are deeply interconnected. In particular, mTOR activation stimulates the activity of the transcription factor Myc, which plays a key role in the metabolic switch following activation by promoting expression of enzymes involved in aerobic glycolysis and other anabolic pathways (17). In addition, mTOR enhances the translation of the mRNA encoding HIF- $1 \alpha$. The increase in HIF- $1 \alpha$ level also facilitates the expression of critical components of the glycolytic pathway and regulates the balance between Treg and inflammatory Th17 differentiation through direct transcriptional activation of ROR $\gamma \mathrm{t}$ thus promoting $\mathrm{T}$ cell differentiation and activation $(40,41)$.

\section{METABOLIC SIGNATURES OF CD4+ T CELL LINEAGES}

The development of an effective and balanced immune response is largely determined by the differentiation status (Naïve/memory) and effector profile of T cells (Th1, Th17, and Treg), and is controlled by distinct metabolic programs (Figure 1C). Each of these lineages has a distinctive functional property, largely determined by the production of a defined subset of cytokines (42). The lineage commitment of activated $\mathrm{T}$ cells is determined by the integration of multiple cues present in the immune microenvironment at the moment of activation. Interestingly, both the metabolic and immunologic programs are coordinated by the mTOR (43). Thus, mTOR activity is required for the differentiation of all the CD4+ T cell effector subsets but not for the differentiation of Tregs $(44,45)$. Indeed, whereas effector $\mathrm{T}$ cells are highly glycolytic, Tregs have a metabolism dominated by the oxidation of fatty acids followed by oxidative phosphorylation (12).

The activity of mTOR not only influences effector versus regulatory decisions, but also plays a critical role in the differentiation of the different effector $\mathrm{T}$ cell profiles. As follows, signaling from the mTORC1 is required for the differentiation of Th1 and Th17 but not of Th2 cells (46). Conversely, the mTOR signaling through mTORC2 is required for the differentiation of Th2 cells (46).

\section{METABOLIC PROGRAMING OF TH1 CELLS}

Th1 cells are functionally characterized by the production of IFN $\gamma$ and TNF, which are of utmost importance in the induction of cell-mediated immunity against obligate intracellular pathogens, such as viruses, as well as bacteria, such as $M$. tuberculosis. Th1 cells possess a high glycolytic rate, which is paralleled by high surface expression levels of Glut1 (12). Remarkably, the glycolytic metabolism of Th1 cells dramatically influences their functionality, as evidenced by the fact that inhibition of glycolysis severely suppresses the secretion of $\operatorname{IFN} \gamma(6$, $10)$. In addition to the role of aerobic glycolysis in biomass production, glycolysis and IFN $\gamma$ production present one extra level of interaction. Indeed, it has been proposed that glycolytic enzymes can regulate the effector phenotype of $\mathrm{T}$ cells by performing non-metabolic functions. For example, the glycolytic enzyme GAPDH, if not engaged in glycolysis, can bind IFN $\gamma$ mRNA post-transcriptionally, blocking the translation of this cytokine. Thus, aerobic glycolysis would be required to engage GAPDH in its metabolic functions, liberating the IFN $\gamma$ mRNA for translation, thereby allowing these cells to attain full effector functions (10). Interestingly, studies conducted by Cham and Gajewski elegantly demonstrated that IFN $\gamma$, but not IL-2, production is preferentially inhibited by limiting glucose conditions (47). This further highlights the important link between glucose metabolism regulated by mTORC1, and CD8+ T cell effector functions. Although inhibition correlated with reduced phosphorylation of p70S6 kinase and eIF4E binding protein 1, surprisingly, inhibition of mTOR failed to block T cell cytokine production under their experimental conditions (47). This illustrates the complex relationship between transcriptional and post 
transcriptional control of $\mathrm{T}$ cell effector functions, mediated by metabolic reprograming.

\section{METABOLIC PROGRAMING OF TH17 CELLS}

Th17 cells produce IL-17, IL-21, and IL-22 and are critical for the control of extracellular bacteria and mucosal immunity. Moreover, Th17 cells are important for of a number of autoimmune processes (48). Like Th1 cells, Th17 cells are highly glycolytic (12). In addition to the requirement of signaling from the mTORC1 (46), Th17 cell differentiation is critically dependent on the transcription factor HIF- $1 \alpha$. HIF- $1 \alpha$ not only stimulates the glycolytic activity of Th17 cells, but also transcriptionally activates the master transcription factor ROR $\gamma \mathrm{t}$ (40), which subsequently directs the differentiation program of Th17 cells (49). Thus, it is therefore clear that metabolic programs can now be used to identify and classify effector $\mathrm{T}$ cell lineages as reviewed by Maclver and colleagues (7).

\section{METABOLIC PROGRAMS IN DIFFERENTIATION AND EXPANSION OF Tregs}

Lipid oxidation via AMPK and oxidative phosphorylation are considered the predominant metabolic programs in differentiated Tregs $(7,12)$. However, Neildez-Nguyen and colleagues have recently shown that higher expression of Glut1 is detected on mouse Tregs generated under hypoxic $\left(5 \% \mathrm{O}_{2}\right)$ culture conditions compared to those cultured under ambient oxygen levels $\left(21 \% \mathrm{O}_{2}\right)(50)$. Indeed following differentiation, amplification of the committed Tregs was explicitly favored by low oxygenation, and by glycolysis probably through induction of Glut1 on the cell membrane (50). This observation underscores the significance of culture conditions such as oxygen levels in regulating metabolism and thus cautions how one interprets and relate in vitro metabolic activity to those in humans. The significance of these distinctions is confirmed by the expression and stability of HIF$1 \alpha$, which is highly dependent on the level of oxygenation in the cellular environment. Augmented Glut1 expression, mediated by HIF- $1 \alpha$, is observed in response to low $\mathrm{O}_{2}$ levels in several cell types including CD4+ T cell (9). HIF-1 $\alpha$ transcriptionally activates genes encoding glucose transporters, and rate limiting enzymes involved in glycolysis, and therefore plays a significant role in $\mathrm{T}$ cell differentiation and functions $(39,51)$.

\section{T CELL METABOLISM IN INFLAMMATORY DISEASES}

Despite the overwhelming evidence suggesting that specific metabolic alterations is associated with $\mathrm{T}$ cell functions and differentiation; how these metabolic changes influences immune functions in human diseases has only recently been examined. Studying Glut1 levels on immune cells, Palmer and co-workers have shown that increased glycolytic metabolism in CD4+ T cells is associated with abnormally high levels of immune activation, and low CD4+ T cell count in HIV-infected persons (52), at least in part due to "metabolic exhaustion" of these cells. Indeed, recent investigations have demonstrated that Glut1 is a CD4+ T cell activation marker essential for cell growth and proliferation, and HIV infection in vitro (9, 53). It is unknown whether other inflammatory conditions such as obesity, diabetes, cardiovascular diseases, and rheumatoid arthritis can impact cellular metabolism of T cells and other immune cells. In the context of HIV infection, an established chronic inflammatory disease, increased glucose metabolism in inflammatory monocyte subsets was associated with elevated levels of markers of inflammation $(54,55)$.

As discussed above, following activation and differentiation, the pro-inflammatory $\mathrm{CD} 4+\mathrm{T}$ cell subsets are distinguished from the anti-inflammatory CD4+ Tregs based on their metabolic signatures. Thus, intense investigations are now focused on the hypothesis that elevated glycolysis is a hallmark of inflammatory cells. Indeed, inhibition of glycolysis by rapamycin has been shown to facilitate the generation of murine naturally occurring CD4+CD25+Foxp3+ Tregs in vitro, which were able to prevent allograft rejection in vivo (56), illustrating the link between $\mathrm{T}$ cell differentiation, metabolism, and immunity.

Recently, the role of oxidative stress, a hallmark in several inflammatory conditions has been discussed in the framework of metabolism in immune cells (1). In inflammatory macrophages, reactive oxygen species (ROS) have been implicated in increased Glut1 expression and glycolysis, mediated in part by NF-kB signaling (1). Data regarding the role of ROS in T cell metabolism are sparse; however, upon $\mathrm{T}$ cell activation, mitochondrial ROS are generated within minutes, and at low levels is associated with cellular proliferation $(57,58)$. Therefore, a plausible model in the context of T cells is that ROS induce HIF- $1 \alpha$ by activating $\mathrm{PI} 3 \mathrm{~K} / \mathrm{mTOR}$ and or NF-kB-linked signaling to upregulate metabolic pathways that facilitate $\mathrm{T}$ cell expansion and proliferation (59). Another important consideration is the interaction between $\mathrm{T}$ cells and other immune cells such as monocytes and macrophages. Inflammatory mediators produced by activated monocytes and macrophages are potential sources of activating stimuli for $\mathrm{T}$ cells (54), thus a thorough understanding of the shared metabolic checkpoints by which diverse inflammatory cues and oxidative stress modulate metabolic programing will provide important insight into combined approaches to target cellular metabolism in T cells. Moreover, the prominence of immune cells in controlling inflammatory-associated inflammation such as obesity has now gained considerable attention (60). The exciting advances in immunometabolism may provide new opportunities to develop novel interventions for the treatment of inflammatory and metabolic diseases.

\section{ACKNOWLEDGMENTS}

Clovis S. Palmer would like to thank Nice-consultants.com for artistic support. Clovis S. Palmer is funded by the Australian Centre for HIV and Hepatitis Virology Research (ACH2). Suzanne M. Crowe is a recipient of a National Health and Medical Research Council of Australia (NHMRC) Principal Research Fellowship. The authors gratefully acknowledge the contribution to this work of the Victorian Operational Infrastructure Support Program received by the Burnet Institute.

\section{REFERENCES}

1. Freemerman AJ, Johnson AR, Sacks GN, Milner JJ, Kirk EL, Troester MA, et al. Metabolic reprogramming of macrophages: glucose transporter 1 (GLUT1)mediated glucose metabolism drives a proinflammatory phenotype. J Biol Chem (2014) 289:7884-96. doi:10.1074/jbc.M113.522037 
2. Jacobs SR, Herman CE, MacIver NJ, Wofford JA, Wieman HL, Hammen JJ, et al. Glucose uptake is limiting in T cell activation and requires CD28-mediated Akt-dependent and independent pathways. J Immunol (2008) 180:4476-86. doi:10.4049/jimmunol.180.7.4476

3. Araki K, Turner AP, Shaffer VO, Gangappa S, Keller SA, Bachmann MF, et al. mTOR regulates memory CD8 T-cell differentiation. Nature (2009) 460:108-12. doi:10.1038/nature08155

4. Man K, Miasari M, Shi W, Xin A, Henstridge DC, Preston S, et al. The transcription factor IRF4 is essential for TCR affinity-mediated metabolic programming and clonal expansion of T cells. Nat Immunol (2013) 14:1155-65. doi:10.1038/ni.2710

5. Fox CJ, Hammerman PS, Thompson CB. Fuel feeds function: energy metabolism and the T-cell response. Nat Rev Immunol (2005) 5:844-52. doi:10.1038/nri1710

6. Zheng Y, Delgoffe GM, Meyer CF, Chan W, Powell JD. Anergic T cells are metabolically anergic. J Immunol (2009) 183:6095-101. doi:10.4049/jimmunol. 0803510

7. MacIver NJ, Michalek RD, Rathmell JC. Metabolic regulation of T lymphocytes. Annu Rev Immunol (2013) 31:259-83. doi:10.1146/annurev-immunol-032712095956

8. Palmer CS, Crowe SM. How does monocyte metabolism impact inflammation and aging during chronic HIV infection? AIDS Res Hum Retroviruses (2014) 30:335-6. doi:10.1089/aid.2014.0022

9. Loisel-Meyer S, Swainson L, Craveiro M, Oburoglu L, Mongellaz C, Costa C, et al. Glut1-mediated glucose transport regulates HIV infection. Proc Natl Acad Sci U S A (2012) 109:2549-54. doi:10.1073/pnas.1121427109

10. Chang CH, Curtis JD, Maggi LB Jr., Faubert B, Villarino AV, O’Sullivan D, et al. Posttranscriptional control of $\mathrm{T}$ cell effector function by aerobic glycolysis. Cell (2013) 153:1239-51. doi:10.1016/j.cell.2013.05.016

11. Pearce EL, Poffenberger MC, Chang CH, Jones RG. Fueling immunity: insights into metabolism and lymphocyte function. Science (2013) 342:1242454. doi:10. 1126/science. 1242454

12. Michalek RD, Gerriets VA, Jacobs SR, Macintyre AN, MacIver NJ, Mason EF, et al. Cutting edge: distinct glycolytic and lipid oxidative metabolic programs are essential for effector and regulatory CD4+ T cell subsets. J Immunol (2011) 186:3299-303. doi:10.4049/jimmunol.1003613

13. Krawczyk CM, Holowka T, Sun J, Blagih J, Amiel E, DeBerardinis RJ, et al. Tolllike receptor-induced changes in glycolytic metabolism regulate dendritic cell activation. Blood (2010) 115:4742-9. doi:10.1182/blood-2009-10-249540

14. Wieman HL, Wofford JA, Rathmell JC. Cytokine stimulation promotes glucose uptake via phosphatidylinositol-3 kinase/Akt regulation of Glutl activity and trafficking. Mol Biol Cell (2007) 18:1437-46. doi:10.1091/mbc.E06-07-0593

15. Wofford JA, Wieman HL, Jacobs SR, Zhao Y, Rathmell JC. IL-7 promotes Glut 1 trafficking and glucose uptake via STAT5-mediated activation of Akt to support T-cell survival. Blood (2008) 111:2101-11. doi:10.1182/blood-200706-096297

16. Ghesquiere B, Wong BW, Kuchnio A, Carmeliet P. Metabolism of stromal and immune cells in health and disease. Nature (2014) 511:167-76. doi:10.1038/ nature 13312

17. Wang R, Dillon Christopher P, Shi Lewis Z, Milasta S, Carter R, Finkelstein D, et al. The transcription factor Myc controls metabolic reprogramming upon T lymphocyte activation. Immunity (2011) 35:871-82. doi:10.1016/j.immuni. 2011.09.021

18. Bauer DE, Harris MH, Plas DR, Lum JJ, Hammerman PS, Rathmell JC, et al. Cytokine stimulation of aerobic glycolysis in hematopoietic cells exceeds proliferative demand. FASEB J (2004) 18:1303-5. doi:10.1096/fj.03-1001fje

19. Frauwirth K, Riley J, Harris M, Parry R, Rathmell J, Plas D, et al. The CD28 signaling pathway regulates glucose metabolism. Immunity (2002) 16:769-77. doi:10.1016/S1074-7613(02)00323-0

20. Jones RG, Thompson CB. Revving the engine: signal transduction fuels $\mathrm{T}$ cell activation. Immunity (2007) 27:173-8. doi:10.1016/j.immuni.2007.07.008

21. Wang T, Marquardt C, Foker J. Aerobic glycolysis during lymphocyte proliferation. Nature (1976) 261:702-5. doi:10.1038/261702a0

22. Warburg O. On respiratory impairment in cancer cells. Science (1956) 124:269-70.

23. Cao Y, Rathmell JC, Macintyre AN. Metabolic reprogramming towards aerobic glycolysis correlates with greater proliferative ability and resistance to metabolic inhibition in CD8 versus CD4 T cells. PLoS One (2014) 9:e104104. doi:10.1371/journal.pone.0104104
24. Chi H. Regulation and function of mTOR signalling in T cell fate decisions. Nat Rev Immunol (2012) 12:325-38. doi:10.1038/nri3198

25. Frauwirth KA, Thompson CB. Regulation of $\mathrm{T}$ lymphocyte metabolism. J Immunol (2004) 172:4661-5. doi:10.4049/jimmunol.172.8.4661

26. Palmer CS, Crowe SM. The role of glucose and lipid metabolism in the pathogenesis of HIV-1 infection. Curr Trends Immunol (2012) 13:37-50.

27. Nath MD, Ruscetti FW, Petrow-Sadowski C, Jones KS. Regulation of the cell-surface expression of an HTLV-I binding protein in human T cells during immune activation. Blood (2003) 101:3085-92. doi:10.1182/blood-200207-2277

28. Chakrabarti R, Jung CY, Lee TP, Liu H, Mookerjee BK. Changes in glucose transport and transporter isoforms during the activation of human peripheral blood lymphocytes by phytohemagglutinin. J Immunol (1994) 152: 2660-8.

29. Finlay DK. Regulation of glucose metabolism in T cells: new insight into the role of phosphoinositide 3-kinases. Front Immunol (2012) 3:247. doi:10.3389/ fimmu.2012.00247

30. Zhang XY, Yang BY, Wang JY, Mo X, Zhang J, Hua ZC. FADD is essential for glucose uptake and survival of thymocytes. Biochem Biophys Res Commun (2014) 451:202-7. doi:10.1016/j.bbrc.2014.07.092

31. Laplante M, Sabatini DM. mTOR signaling at a glance. J Cell Sci (2009) 122:3589-94. doi:10.1242/jcs.051011

32. Laplante M, Sabatini DM. mTOR signaling in growth control and disease. Cell (2012) 149:274-93. doi:10.1016/j.cell.2012.03.017

33. Sun SY. mTOR kinase inhibitors as potential cancer therapeutic drugs. Cancer Lett (2013) 340:1-8. doi:10.1016/j.canlet.2013.06.017

34. Marko AJ, Miller RA, Kelman A, Frauwirth KA. Induction of glucose metabolism in stimulated $\mathrm{T}$ lymphocytes is regulated by mitogen-activated protein kinase signaling. PLoS One (2010) 5:e15425. doi:10.1371/journal.pone.0015425

35. Tamas P, Hawley SA, Clarke RG, Mustard KJ, Green K, Hardie DG, et al. Regulation of the energy sensor AMP-activated protein kinase by antigen receptor and Ca2+ in T lymphocytes. J Exp Med (2006) 203:1665-70. doi:10.1084/jem. 20052469

36. Chehtane M, Khaled AR. Interleukin-7 mediates glucose utilization in lymphocytes through transcriptional regulation of the hexokinase II gene. Am J Physiol Cell Physiol (2010) 298:C1560-71. doi:10.1152/ajpcell.00506.2009

37. Sun Q, Chen X, Ma J, Peng H, Wang F, Zha X, et al. Mammalian target of rapamycin up-regulation of pyruvate kinase isoenzyme type M2 is critical for aerobic glycolysis and tumor growth. Proc Natl Acad Sci U S A (2011) 108:4129-34. doi:10.1073/pnas.1014769108

38. Yu BH, Zhou XY, Xiao XY, Yan SY, Qin T, Shi DR. [Activation and clinicopathologic significance of AKT/mTOR signaling pathway in diffuse large B-cell lymphoma]. Zhonghua Bing Li Xue Za Zhi (2009) 38:35-41.

39. Oestreich KJ, Read KA, Gilbertson SE, Hough KP, McDonald PW, Krishnamoorthy $\mathrm{V}$, et al. Bcl-6 directly represses the gene program of the glycolysis pathway. Nat Immunol (2014) 15:957-64. doi:10.1038/ni.2985

40. Dang EV, Barbi J, Yang HY, Jinasena D, Yu H, Zheng Y, et al. Control of $\mathrm{T}(\mathrm{H}) 17 / \mathrm{T}$ (reg) balance by hypoxia-inducible factor 1. Cell (2011) 146:772-84. doi:10.1016/j.cell.2011.07.033

41. Shi LZ, Wang R, Huang G, Vogel P, Neale G, Green DR, et al. HIFlalphadependent glycolytic pathway orchestrates a metabolic checkpoint for the differentiation of TH17 and Treg cells. J Exp Med (2011) 208:1367-76. doi:10.1084/ jem. 20110278

42. Wan YY, Flavell RA. How diverse-CD4 effector T cells and their functions. JMol Cell Biol (2009) 1:20-36. doi:10.1093/jmcb/mjp001

43. Waickman AT, Powell JD. mTOR, metabolism, and the regulation of T-cell differentiation and function. Immunol Rev (2012) 249:43-58. doi:10.1111/j.1600065X.2012.01152.x

44. Delgoffe GM, Kole TP, Zheng Y, Zarek PE, Matthews KL, Xiao B, et al. The mTOR kinase differentially regulates effector and regulatory $\mathrm{T}$ cell lineage commitment. Immunity (2009) 30:832-44. doi:10.1016/j.immuni.2009.04.014

45. Gaber T, Strehl C, Sawitzki B, Hoff P, Buttgereit F. Cellular energy metabolism in T-lymphocytes. Int Rev Immunol (2014). doi:10.3109/08830185.2014. 956358

46. Delgoffe GM, Pollizzi KN, Waickman AT, Heikamp E, Meyers DJ, Horton MR, et al. The kinase mTOR regulates the differentiation of helper $\mathrm{T}$ cells through the selective activation of signaling by mTORC1 and mTORC2. Nat Immunol (2011) 12:295-303. doi:10.1038/ni.2005 
47. Cham CM, Gajewski TF. Glucose availability regulates IFN-gamma production and p70S6 kinase activation in CD8+ effector T cells. J Immunol (2005) 174:4670-7. doi:10.4049/jimmunol.174.8.4670

48. Peters A, Lee Y, Kuchroo VK. The many faces of Th17 cells. Curr Opin Immunol (2011) 23:702-6. doi:10.1016/j.coi.2011.08.007

49. Ivanov II, McKenzie BS, Zhou L, Tadokoro CE, Lepelley A, Lafaille JJ, et al. The orphan nuclear receptor RORgammat directs the differentiation program of proinflammatory IL-17+ T helper cells. Cell (2006) 126:1121-33. doi:10.1016/j.cell.2006.07.035

50. Neildez-Nguyen TM, Bigot J, Da Rocha S, Corre G, Boisgerault F, Paldi A, et al. Hypoxic culture conditions enhance the generation of regulatory $\mathrm{T}$ cells. Immunology (2014). doi:10.1111/imm.12388

51. Chen C, Pore N, Behrooz A, Ismail-Beigi F, Maity A. Regulation of glut1 mRNA by hypoxia-inducible factor-1. Interaction between $\mathrm{H}$-ras and hypoxia. J Biol Chem (2001) 276:9519-25. doi:10.1074/jbc.M010144200

52. Palmer CS, Ostrowski M, Gouillou M, Tsai L, Yu D, Zhou J, et al. Increased glucose metabolic activity is associated with CD4+ T-cell activation and depletion during chronic HIV infection. AIDS (2014) 28:297-309. doi:10.1097/QAD. 0000000000000128

53. Macintyre AN, Gerriets VA, Nichols AG, Michalek RD, Rudolph MC, Deoliveira $\mathrm{D}$, et al. The glucose transporter Glutl is selectively essential for CD4 T cell activation and effector function. Cell Metab (2014) 20:61-72. doi:10.1016/j.cmet. 2014.05.004

54. Anzinger JJ, Butterfield TR, Angelovich TA, Crowe SM, Palmer CS. Monocytes as regulators of inflammation and HIV-related comorbidities during cART. J Immunol Res (2014) 2014:569819. doi:10.1155/2014/569819

55. Palmer CS, Anzinger JJ, Zhou J, Gouillou M, Landay A, Jaworowski A, et al. Glutl expressing pro-inflammatory monocytes are elevated in cART-treated and untreated HIV-1+ subjects. J Immunol (2014) 193:5595-603. doi:10.4049/ jimmunol.1303092

56. Battaglia M, Stabilini A, Roncarolo MG. Rapamycin selectively expands CD4+CD25+FoxP3+ regulatory T cells. Blood (2005) 105:4743-8. doi:10.1182/ blood-2004-10-3932
57. Sena LA, Li S, Jairaman A, Prakriya M, Ezponda T, Hildeman DA, et al. Mitochondria are required for antigen-specific $\mathrm{T}$ cell activation through reactive oxygen species signaling. Immunity (2013) 38:225-36. doi:10.1016/j.immuni. 2012.10.020

58. Devadas S, Zaritskaya L, Rhee SG, Oberley L, Williams MS. Discrete generation of superoxide and hydrogen peroxide by $\mathrm{T}$ cell receptor stimulation: selective regulation of mitogen-activated protein kinase activation and fas ligand expression. J Exp Med (2002) 195:59-70. doi:10.1084/jem.20010659

59. Fracchia KM, Walsh CM. Metabolic mysteries of the inflammatory response: $\mathrm{T}$ cell polarization and plasticity. Int Rev Immunol (2014). doi:10.3109/08830185. 2014.974748

60. Winer S, Chan Y, Paltser G, Truong D, Tsui H, Bahrami J, et al. Normalization of obesity-associated insulin resistance through immunotherapy. Nat Med (2009) 15:921-9. doi:10.1038/nm.2001

Conflict of Interest Statement: The authors declare that the research was conducted in the absence of any commercial or financial relationships that could be construed as a potential conflict of interest.

Received: 02 December 2014; paper pending published: 16 December 2014; accepted: 02 January 2015; published online: 22 January 2015.

Citation: Palmer CS, Ostrowski M, Balderson B, Christian N and Crowe SM (2015) Glucose metabolism regulates $T$ cell activation, differentiation, and functions. Front. Immunol. 6:1. doi: 10.3389/fimmu.2015.00001

This article was submitted to T Cell Biology, a section of the journal Frontiers in Immunology.

Copyright (C) 2015 Palmer, Ostrowski, Balderson, Christian and Crowe. This is an open-access article distributed under the terms of the Creative Commons Attribution License (CC BY). The use, distribution or reproduction in other forums is permitted, provided the original author(s) or licensor are credited and that the original publication in this journal is cited, in accordance with accepted academic practice. No use, distribution or reproduction is permitted which does not comply with these terms. 